Review

\title{
Arguments for Using Direct Oral Anticoagulants in Cancer-Related Venous Thromboembolism
}

\author{
Roxana Mihaela Chiorescu 1,2 (D), Mihaela Mocan 1,2,*(D), Mirela Anca Stoia 1,3, Anamaria Barta 1,4, \\ Cerasela Mihaela Goidescu 1,5 ${ }^{1}$, Stefan Chiorescu ${ }^{6}$ and Anca Daniela Farcaş 1,3
}

1 Internal Medicine Department, Iuliu Hatieganu University of Medicine and Pharmacy, 400012 Cluj-Napoca, Romania; chiorescu.roxana@umfcluj.ro (R.M.C.); mirelastoia@yahoo.com (M.A.S.); apicrek@yahoo.com (A.B.); ceraselagoidescusava@yahoo.com (C.M.G.); ancafarcas@yahoo.com (A.D.F.) 2 Department of Internal Medicine, Emergency Clinical County Hospital, 400006 Cluj-Napoca, Romania 3 Department of Cardiology, Emergency Clinical County Hospital, 400006 Cluj-Napoca, Romania

4 Department of Cardiology, "Nicolae Stăncioiu" Heart Institute, 400001 Cluj-Napoca, Romania

5 Department of Cardiology, Military Emergency Hospital “C. Papilian”, 400132 Cluj-Napoca, Romania

6 Surgery Department, Iuliu Hatieganu University of Medicine and Pharmacy, 400012 Cluj-Napoca, Romania; stefanc74@yahoo.com

* Correspondence: mihaela.mocan@gmail.com; Tel.: +40-765-258-870

check for updates

Citation: Chiorescu, R.M.; Mocan, M.; Stoia, M.A.; Barta, A.; Goidescu, C.M.; Chiorescu, S.; Farcaş, A.D. Arguments for Using Direct Oral Anticoagulants in Cancer-Related Venous Thromboembolism. Healthcare 2021, 9, 1287. https://doi.org/ 10.3390/healthcare9101287

Academic Editors: Reza Mortazavi and Salvatore De Rosa

Received: 19 August 2021

Accepted: 23 September 2021

Published: 28 September 2021

Publisher's Note: MDPI stays neutral with regard to jurisdictional claims in published maps and institutional affiliations.

Copyright: (c) 2021 by the authors. Licensee MDPI, Basel, Switzerland. This article is an open access article distributed under the terms and conditions of the Creative Commons Attribution (CC BY) license (https:/ / creativecommons.org/licenses/by/ $4.0 /$ )
Abstract: (1) Background: Patients with cancer with a hypercoagulable state present an increased incidence of venous thromboembolism (VTE). Neoplastic patients with concurrent VTE undergoing anticoagulant treatment face a series of issues. (2) The aim of the present paper is to systematically summarize current VTE management in patients with neoplasia and to review the current clinical evidence from meta-analyses of randomized controlled trials and guidelines regarding the administration of direct oral anticoagulants (DOACs) for cancer-associated VTE. (3) Search Strategy: We performed a review on meta-analyses of randomized controlled trials and guidelines in favor of the administration of DOACs in patients with cancer-associated VTE published in the last 6 years in the Medline (PubMed) and Embase databases. (4) Results: 21 meta-analyses, 14 randomized controlled studies comparing DOACs to VKAs and LMWH, and 7 national and international guidelines were identified. We identified five studies that show the antineoplastic effect of DOAC on experimental models. (5) Conclusions: DOACs can be seen as the first choice for VTE treatment in neoplastic patients who have a low risk of bleeding, who do not have severe renal impairment, and who are not undergoing treatments that could interact with DOAC's mechanism of action.

Keywords: direct oral anticoagulants; cancer-associated venous thromboembolism

\section{Introduction}

Venous thromboembolism (VTE) is the second most frequent cause of death in patients with neoplasia undergoing chemotherapy, while the main cause of death in these patients is the progression of the neoplasm [1].

The association of cancer with VTE determines a 30 times higher risk of death as compared to the general population. The association of cancer with VTE increases the rate of mortality exponentially, which is 10 times higher than in the case of VTE patients without neoplasia and four times higher than in neoplastic patients without VTE [2].

The hypercoagulable state in neoplasia can be explained by the multiple physiopathological mechanisms present in oncogenesis: (1) the production of procoagulant and angiogenic substances induced by tumor hypoxemia; (2) the changes in the thrombocyteendothelium interaction and in the cascade of coagulation and fibrinolysis, i.e., there is an increase in the concentration of thrombocyte-activating factors (P-selectin, soluble CD40 ligand, and platelet factor); (3) changes in the concentration of the tissue factor responsible for the initiation of coagulation; (4) the synthesis of a protease capable of directly activating factor Xa [3]. 
Anticoagulant treatment in patients with cancer-associated VTE faces a number of problems such as increased risk of bleeding, high risk of VTE recurrence, interactions with the specific treatment of neoplasia, and the need for a long-term administration of the treatment. Recently, the standard of care of cancer-associated VTE consisted of subcutaneous low-molecular-weight heparin (LMWH) for an initial duration of 6 months, which was extended with either LMWH or vitamin K antagonists (VKA) for an indefinite duration, i.e., until the cancer was considered to be in remission [4]. The administration of LMWHs faces a series of drawbacks connected especially with the manner of administration, which leads to a decrease in treatment compliance and an increase in the risk of VTE recurrence [5].

The aim of the present paper was to systematically summarize current VTE management in patients with neoplasia and to review the current clinical evidence from metaanalyses of randomized controlled trials and guidelines in favor of the administration of DOACs in this category of patients.

\section{Materials and Methods}

\subsection{Search Strategy}

The search strategy was performed according to a predefined protocol and complied with the PRISMA guidelines [6], as shown in Figure 1.
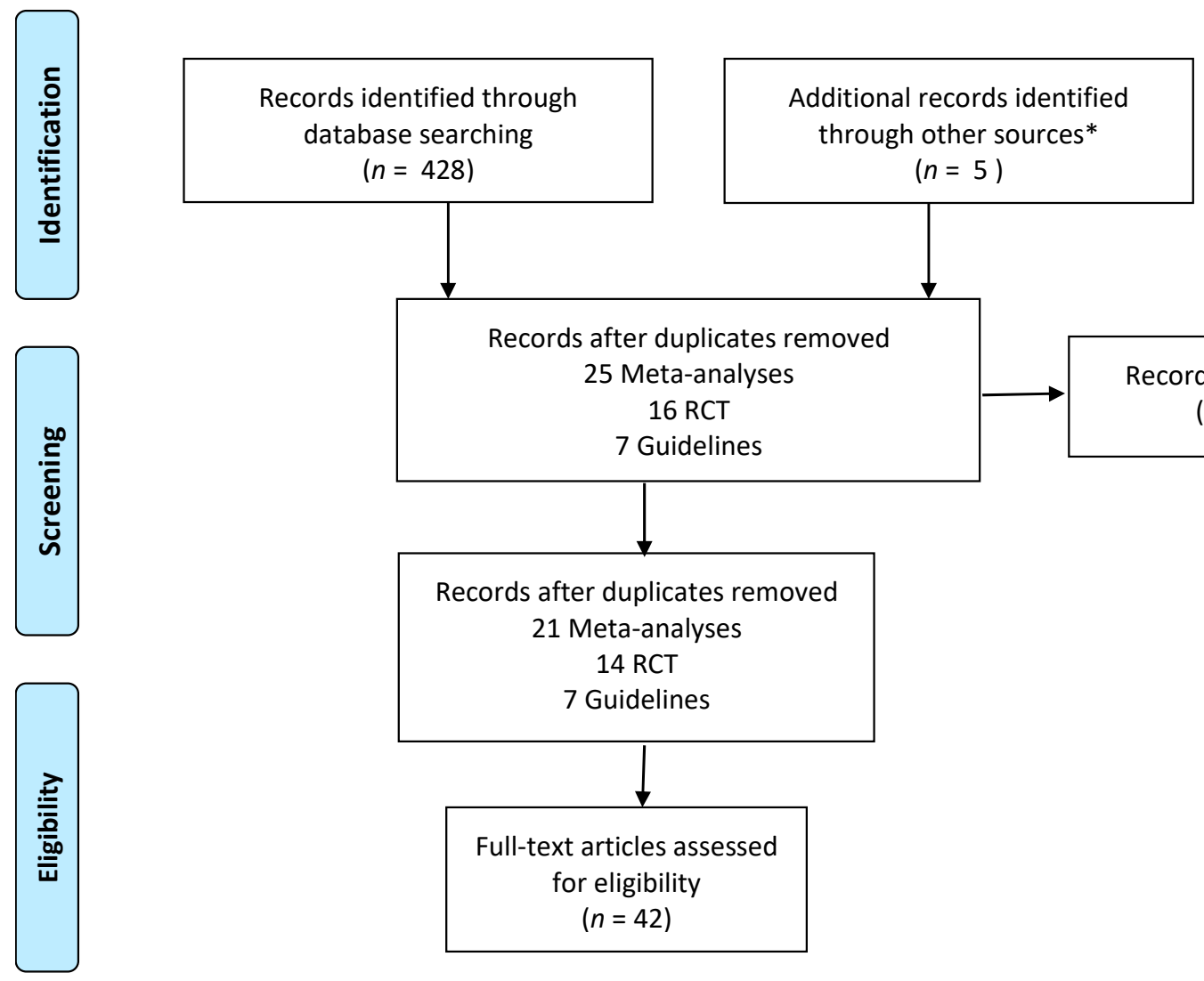

Figure 1. The algorithm showing the identification of articles included in the review. ${ }^{*}$ Other sources: references from meta-analyses and guidelines.

\subsection{Information Sources}

Two authors systematically searched the PubMed and Embase databases using the following combination of keywords: "cancer related thromboembolism DOAC", "cancer thromboembolism DOAC", "cancer thromboembolism DOAC", "cancer thromboembolism dabigatran", "cancer thromboembolism direct thrombin inhibitor", "cancer thromboembolism rivaroxaban", "cancer thromboembolism apixaban", "cancer thromboembolism 
edoxaban", "cancer thromboembolism factor Xa inhibitor". Apart from these keywords, "the antineoplastic effect of DOAC on experimental models" was searched on Pub Med.

\subsection{Eligibility Criteria}

We included meta-analyses of large studies and of randomized controlled trials and practice guidelines of national and international societies, referring to DOAC prescription in patients with VTE associated with neoplasia. Two authors independently evaluated the studies for possible inclusion. Non-relevant studies were excluded based on their titles and abstracts. For potentially relevant studies, a full text was obtained. The research was restricted to meta-analyses of large studies and of randomized controlled trials and practice guidelines published in the past 6 years (January 2015-December 2020).

\section{Results}

The flow diagram of the evaluation process is shown in Figure 1. The literature search yielded a total of 393 related articles. After duplicates were removed, 42 articles remained.

\subsection{Meta-Analyses}

The 21 meta-analyses published in the past 6 years are shown in Table 1. Several metaanalyses focusing on the efficacity and safety of DOACs in cancer-associated VTE were identified. Efficiency was assessed according to the recurrence rate and safety as related to major bleeding and clinically relevant nonmajor bleeding (CRNMB). Comparisons between DOACs, LMWH, and VKAs were analyzed. The most important conclusion drawn from these extensive analyses was that DOACs demonstrate a similar efficiency and safety as compared to LMWH and VKAs in cancer-associated VTE $[7,8]$.

Table 1. Meta-analysis published in the past 6 years.

\begin{tabular}{|c|c|c|}
\hline Meta-Analysis & Publication Year & Results \\
\hline 1. Sardar, P. [7] & $\begin{array}{l}2015 ; 19,832 \text { pts and } \\
1197 \text { pts. }\end{array}$ & $\begin{array}{l}\text { DOACs administered in patients with cancer were found to be as safe } \\
\text { and efficient as is the case in patients without cancer. Rivaroxaban might } \\
\text { be effective and safe in patients with cancer, as compared to VKA [6]. }\end{array}$ \\
\hline 2. Posch, F. [8] & $2015 ; 3242$ pts & $\begin{array}{l}\text { DOACs have similar efficacity and safety to LMWH in patients with } \\
\text { cancer [7]. }\end{array}$ \\
\hline 3. Mantha, S. [9] & 2015 & $\begin{array}{l}\text { Apixaban appears to be safer than other oral anticoagulants, with a lower } \\
\text { risk of bleeding in patients with cancer [8]. }\end{array}$ \\
\hline 4. Boonyawat, K. [10] & $2017 ; 98.244$ pts & $\begin{array}{l}\text { When the influence of body weight on DOAC efficiency was assessed, } \\
\text { the results showed that it is not recommended to adjust the doses of } \\
\text { DOACs outside the already known limits [9]. }\end{array}$ \\
\hline 5. Kahale, LA. [11] & $2017 ; 1486$ pts & $\begin{array}{l}\text { DOACs do not decrease mortality in cancer patients but may be } \\
\text { responsible for more bleeding events [10]. }\end{array}$ \\
\hline 6. Kahale, LA. [12] & $2018 ; 5167$ & $\begin{array}{l}\text { For long-term therapy for cancer-associated thrombotic events, DOACs, } \\
\text { as compared to LMWH, may have an efficient antithrombotic effect, but } \\
\text { safety issues arise because of an increased risk of major bleeding [11]. }\end{array}$ \\
\hline 7. Vedovati, MC. [13] & $2018 ; 1430$ pts & $\begin{array}{l}\text { In patients with cancer and VTE, DOACs were showed to be safe and } \\
\text { efficient as compared to LMWHs [12]. }\end{array}$ \\
\hline 8. Xing, J. [14] & $2018 ; 667$ pts & $\begin{array}{l}\text { Rivaroxaban proved to be efficient and safe as compared to LWMH } \\
\text { (enoxaparin for the prevention of recurrent thrombotic events in } \\
\text { neoplastic patients). Thus, rivaroxaban was recommended as a } \\
\text { therapeutic option for cancer-associated VTE [13]. }\end{array}$ \\
\hline 9. Martinez, BK. [15] & $2018 ; 949$ pts & $\begin{array}{l}\text { Rivaroxaban demonstrated similar levels of safety (rate of major } \\
\text { bleeding) and efficiency (recurrent VTE) to the other anticoagulants for } \\
\text { patients with cancer-associated VTE. The mortality was lower than } \\
\text { reported in many anticoagulation CAT trials [14]. }\end{array}$ \\
\hline
\end{tabular}


Table 1. Cont.

\begin{tabular}{ccc}
\hline Meta-Analysis & Publication Year & Results \\
\hline 10. Park, H. [16] & 2018 & $\begin{array}{c}\text { For the treatment of cancer-associated VTE, DOACs proved to be safer } \\
\text { and more efficient as compared to VKA. DOACs could be one of the } \\
\text { standard therapeutic options in neoplastic patients. Among DOACs, } \\
\text { apixaban exhibited a better outcome [15]. }\end{array}$ \\
\hline 11. Hong, Y. [17] & 2018 & $\begin{array}{r}\text { Rivaroxaban was associated with a lower hospital admission rate as } \\
\text { compared to LWMH [16]. }\end{array}$ \\
\hline
\end{tabular}
12. Gómez-Outes, A. $\quad 2018 ; 29,844$ pts
[18]

13. Li, A. [19]

2019

The type of anticoagulation made no difference in the overall survival or causes of death, while the presence of active cancer was associated with a poor outcome and a higher mortality rate [17].

DOACs proved to be more effective than LMWHs in secondary prevention of VTE. Unfortunately, DOACs had a low safety profile as a result of increasing the risk of major bleeding and CRNMB, even though the absolute risk differences were small (2-3\%). Better compliance with

DOACs than LMWHs was hypothesized to explain the differences in bleeding events [18].

DOACs proved efficient in secondary prevention of VTE in neoplastic patients but showed a low safety profile with an increased risk of bleeding as compared to LMWH [19].

14. Rossel, A. [20] 2019; 4667 pts

$2019 ; 6980$ pts

DOACs were more effective than LMWHs in preventing VTE recurrence

15. Kirkilesis, GI. [21] but may carry a higher risk of major bleeding [20].

16. Massimiliano, Camilli [22]

2020,2894 pts

As compared to LMWH, DOACs were associated with a significantly lower risk of VTE recurrence and were not associated with an increased risk of major bleeding; however, they were associated with an increased risk of nonmajor bleeding and gastrointestinal bleeding [21].

DOACs proved to be more effective in secondary prevention of VTE and

17. Desai, R. [23] 2020, 18,945 pts were associated with a small risk of CRNMB. DOACs were considered to only be safe in the appropriately selected neoplastic patients [22].

DOACs demonstrated similar efficiency and safety to dalteparin in

19. Sabatino, I. [24]

$2020 ; 2907$ pts preventing CAT VTE recurrence. However, DOACs were associated with higher rates of nonmajor bleeding as compared with dalteparin, primarily in patients with gastrointestinal malignancies [23].

DOACs were efficient in terms of lowering the risk of VTE or recurrent

VTE in patients with cancer but demonstrated safety issues regarding the increased risk in major and nonmajor bleeding events without influencing the survival rate [24].

20. Desai, A. [25] 2020; 4341 pts

DOACs for VTE treatment and secondary prophylaxis in neoplastic patients proved to be more effective than LMWH but with safety issues related to major and nonmajor bleeding events, especially in those with digestive cancers [25].

CAT—cancer-associated thrombosis; CRNMB—clinically relevant nonmajor bleeding; DOAC—direct oral anticoagulant; PE—pulmonary embolism; VKA—vitamin K antagonist; LMWH—low-molecular-weight heparin; VTE—venous thromboembolism.

\subsection{Randomized Controlled Studies}

Randomized controlled studies comparing DOACs to VKAs and LMWH respectively offer encouraging arguments with regard to the administration of DOACs in paraneoplastic VTE patients (Table 2). Multiple clinical trials compared the efficacy and safety of DOAC vs. LMWH administration in neoplastic patients with VTE. The VTE-recurrence risk was assessed, as was the risk of fatal and nonfatal hemorrhage recurrence under the two types of anticoagulants. 
Table 2. Randomized controlled studies comparing DOACs to VKAs and LMWH, respectively.

\begin{tabular}{|c|c|c|c|c|}
\hline Name of Study & DOAC & $\begin{array}{c}\text { Active Cancer } \\
\text { Randomization }(n)\end{array}$ & $\begin{array}{l}\text { Efficacy End Point } \\
\text { (Recurrent VTE) } \\
\text { Rate HR (95\% CI) }\end{array}$ & $\begin{array}{l}\text { Safety End Point } \\
\text { (Major Bleeding) } \\
\text { Rate HR (95\% CI) }\end{array}$ \\
\hline \multicolumn{5}{|c|}{ DOAC vs. VKA } \\
\hline 1. RE-COVER I/II [27] & Dabigatran & 114 vs. 107 & $\begin{array}{l}3.5 \% \text { vs. } 4.7 \% \\
0.74(0.20-2.7)\end{array}$ & $\begin{array}{c}13 \% \text { vs. } 9 \% \\
1.48(0.64-3.4)\end{array}$ \\
\hline $\begin{array}{l}\text { 2. EINSTEIN-DVT/PE } \\
{[28]}\end{array}$ & Rivaroxaban & 258 vs. 204 & $\begin{array}{c}2 \% \text { vs. } 4 \% \\
0.62(0.21-1.79)\end{array}$ & $\begin{array}{c}12 \% \text { vs. } 13 \% \\
0.82(0.48-1.38)\end{array}$ \\
\hline 3. AMPLIFY [29] & Apixaban & 88 vs. 81 & $\begin{array}{c}3.7 \% \text { vs. } 6.4 \% \\
0.56(0.13-2.37)\end{array}$ & $\begin{array}{c}2.3 \% \text { vs. } 5 \% \\
0.45(0.08-2.46)\end{array}$ \\
\hline 4. HOKUSAI-VTE [30] & Edoxaban & 85 vs. 77 & $\begin{array}{c}2 \% \text { vs. } 9 \% \\
0.30(0.06-1.51)\end{array}$ & $\begin{array}{c}19 \% \text { vs. } 26 \% \\
0.66(0.34-1.27)\end{array}$ \\
\hline \multicolumn{5}{|c|}{ DOAC vs. LMWH } \\
\hline 5. SELECT-D [31] & Rivaroxaban & 203 vs. 203 & $\begin{array}{c}4 \% \text { vs. } 11 \% \\
0.43(0.19-0.99) \\
\end{array}$ & $\begin{array}{c}6 \% \text { vs. } 4 \% \\
1.83(0.68-4.96) \\
\end{array}$ \\
\hline 6. XALIA [32] & Rivaroxaban & 146 vs. 223 & $3.4 \%$ vs. $4.5 \%$ & $1.4 \%$ vs. $3.6 \%$ \\
\hline 7. MSK [33] & Rivaroxaban & 200 & $4.4 \%$ & $2.2 \%$ \\
\hline 8. ADAM-VTE [34] & Apixaban & 145 vs. 142 & $\begin{array}{l}3.4 \% \text { vs. } 14.1 \% \\
0.26(0.09-0.80)\end{array}$ & $\begin{array}{c}0 \% \text { vs. } 2.1 \% \\
p=0.9956\end{array}$ \\
\hline $\begin{array}{l}\text { 9. HOKUSAI-VTE } \\
\text { CANCER [30] }\end{array}$ & Edoxaban & 522 vs. 524 & $\begin{array}{c}7.9 \% \text { vs. } 11.3 \% \\
\quad p=0.09\end{array}$ & $\begin{array}{c}6.9 \% \text { vs. } 4 \% \\
p=0.04\end{array}$ \\
\hline 10. CARAVAGGIO [35] & Apixaban & 576 vs. 579 & $\begin{array}{c}5.6 \% \text { vs. } 7.9 \% \\
0.63(0.37-1.07)\end{array}$ & $\begin{array}{c}3.8 \% \text { vs. } 4.0 \% \\
0.82(0.40-1.69)\end{array}$ \\
\hline 11. CANVAS [36] & $\begin{array}{l}\text { Rivaroxaban, Apixaban, } \\
\text { Edoxaban, Dabigatran }\end{array}$ & 811 & ongoing study & ongoing study \\
\hline 12. CONKO-011 [37] & Rivaroxaban & 450 & ongoing study & ongoing study \\
\hline 13. CASTA-DIVA [38] & Rivaroxaban & 159 & ongoing study & ongoing study \\
\hline 14. COSIMO [39] & Rivaroxaban & 528 & ongoing study & ongoing study \\
\hline
\end{tabular}

CI—confidence interval; DOAC—direct oral anticoagulant; HR—hazard ratio; PE—pulmonary embolism; VKA—vitamin K antagonist; LMWH-low-molecular-weight heparin; VTE—venous thromboembolism.

\subsection{Guidelines Published in the Past 6 Years}

Guidelines published in the past 6 years that recommend the use of DOACs in neoplastic patients with VTE are summarized in Table 3. Practice guidelines play a crucial role in modern medicine. The information found in the guidelines was extracted from RCT and meta-analyses for the clinicians to apply in real-life patients. 
Table 3. Guidelines published in the past 6 years.

\section{Society}

1. Treatment algorithm in

cancer-associated thrombosis: Canadian

expert consensus (2018) [40]

2. ISTH (2018) [41]

4. ACCP (2019) [43]

\section{Recommendations}

1. Does not mention anticoagulation counterindications.

2. DOACs are preferred to LMWH if the hemorrhagic risk is low, in the absence of gastrointestinal tumors, genitourinary tumors, and if there are no drug interactions.

3. The treatment is recommended for 3 months with re-evaluation at the end of the treatment for cancer evolution and type (active/inactive).

1. We suggest the use of specific DOACs (edoxaban or rivaroxaban) for acute VTE in patients with cancer who present a low risk of bleeding and no drug-drug interactions with current systemic therapy. LMWHs are considered an acceptable alternative.

2. Currently, edoxaban and rivaroxaban are the only DOACs with RCT evidence when compared to LMWH in cancer populations.

3. We suggest the use of LMWHs in cancer patients with an acute diagnosis of VTE and high risk of bleeding (luminal gastrointestinal cancer, genitourinary tract cancer, bladder or nephrostomy tubes, or in patients with active gastrointestinal mucosal abnormalities, such as duodenal ulcers, gastritis, esophagitis, or colitis).

4. We recommended individualized treatment by including patients' preferences and values.

1. Weight-adjusted subcutaneous LMWH should be considered for the first 6 months over VKAs (IIa A)

2. Edoxaban should be considered as an alternative to LWMH in patients without gastrointestinal cancer (IIa B).

3. Rivaroxaban should be considered as an alternative to LWMH in patients without gastrointestinal cancer (IIa C).

4. Extended anticoagulation (> 6 months) should be considered for an indefinite period or until cancer is cured (IIa B)

5. Incidental PE should be managed as symptomatic PE if it involves segmental or more proximal branches, multiple subsegmental vessels, or a subsegmental vessel in association with confirmed DVT.

1. We suggest the use of specific DOACs for cancer patients with an acute diagnosis of VTE, low risk of bleeding, and no drug-drug interactions with current systemic therapy. LMWHs are an acceptable alternative.

2. Currently, edoxaban and rivaroxaban are the only DOACs with RCT evidence when compared to LMWH in cancer populations.

3. We suggest the use of LMWHs for cancer patients with an acute diagnosis of VTE and a high risk of bleeding (luminal gastrointestinal cancer and genitourinary tract cancer).

1. Initial anticoagulation may involve LMWH, UFH, fondaparinux, or rivaroxaban. LMWH is preferred over UFH for the initial 5-10 days of anticoagulation (evidence quality: high; strength of recommendation: strong) in patients initiating treatment with parenteral anticoagulation.

2. For long-term anticoagulation treatment, LMWH, edoxaban, or rivaroxaban are preferred for at least 6 months because of improved efficacy over VKAs (evidence quality: high; strength of recommendation: strong).

5. $\operatorname{ASCO}(2019)[44]$

3. Anticoagulation with LMWH, DOACs, or VKAs beyond the initial 6 months should be offered to patients with active cancer, such as those with metastatic disease or those receiving chemotherapy.

4. The insertion of a vena cava filter may be offered as an adjunct to anticoagulation in patients with progression of thrombosis despite optimal anticoagulant therapy.

5. Incidental PE and deep vein thrombosis should be treated in the same manner as symptomatic VTE, given their similar clinical outcomes when compared to cancer patients with symptomatic events.

6. Anticoagulant use is not recommended in order to improve survival in patients with cancer without VTE. 
Table 3. Cont.

\section{Society}

6. Thrombosis and Hemostasis Society of Australia and New Zealand (2019) [45]

Cancer-Associated Venous Thromboembolic Disease (2019) [46]

\section{Recommendations}

1. For DVT or PE that is provoked by active cancer, treatment with therapeutic LMWH for at least 6 months should be administered (evidence: high; strength of recommendation: strong).

2. Patients with incidental PE should be treated in a similar way to patients with symptomatic cancer-associated thrombosis.

3. Edoxaban and rivaroxaban have been shown to be as efficacious as dalteparin in cancer-related thrombosis, but they are associated with an increased risk of major bleeding or CRNMB and, therefore, can be considered when appropriate.

1. For noncatheter-associated DVT or PE, indefinite anticoagulation should be recommended while cancer is active, under treatment, or if risk factors

for recurrence persist.
2. Apixaban is an option for anticoagulation in patients with cancer and should be limited to patients who refuse or have compelling reasons to avoid LMWH.

3. LMWH/UFH plus dabigatran is a potential treatment option for cancer-associated VTE and should be limited to those patients who refuse or have compelling reasons to avoid long-term LMWH.

4. LMWH followed by edoxaban is the first option for anticoagulation in cancer-associated VTE

5. Rivaroxaban is an option for anticoagulation treatment of VTE in patients with cancer. Unlike single-agent apixaban, it is not limited to patients with compelling reasons to avoid LMWH.

6. For catheter-associated thrombosis, anticoagulant therapy should be administered if a catheter is in place. The recommended total duration of the therapy is at least 3 months.

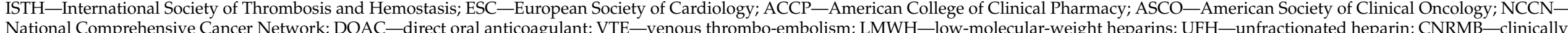
relevant nonmajor bleeding; PE—pulmonary embolism; VKAs—vitamin K antagonists; RCT—randomized controlled trials. 


\subsection{DOACs beyond Anticoagulation: A Potential Antineoplastic Effect}

The studies that assessed the antineoplastic effect in experimental models are presented in Table 4.

Table 4. The studies that showed a favorable antineoplastic effect of DOACs in experimental model.

\begin{tabular}{|c|c|c|c|}
\hline Authors & $\begin{array}{l}\text { Cancer Model/No. of Animals } \\
\text { (Mice) Per Experimental Group }\end{array}$ & $\begin{array}{l}\text { Treatment (Dose, Mode, } \\
\text { Duration, and Timing) }\end{array}$ & Results \\
\hline $\begin{array}{l}\text { DeFeo et al. (2010) } \\
\text { [47] }\end{array}$ & $\begin{array}{l}\text { syngeneic; orthotopic breast cancer } \\
\text { model } / 4-10\end{array}$ & $\begin{array}{c}\text { Dabigatran [ } 45 \mathrm{mg} / \mathrm{kg} \text { body } \\
\text { weight twice a day (Mon-Fri) or } \\
60 \mathrm{mg} / \mathrm{kg} \text { once a day (Sat, Sun) by } \\
\text { oral gavage for } 4 \text { weeks, } \\
\text { beginning } 1 \text { day before tumor } \\
\text { cell injection] }\end{array}$ & $\begin{array}{c}\text { Reduced liver } \\
\text { micrometastases } \\
\text { (no significant effect on lung } \\
\text { micrometastases) }\end{array}$ \\
\hline \multirow{3}{*}{$\begin{array}{l}\text { Graf et al. (2019) } \\
\text { [47] }\end{array}$} & $\begin{array}{l}\text { syngeneic; s.c. } \\
\text { fibrosarcoma model/9 }\end{array}$ & $\begin{array}{l}\text { Rivaroxaban }[0.4 \mathrm{mg} / \mathrm{g} \text { chow diet } \\
\text { for } 8 \text { days, started } 14 \text { days after } \\
\text { cancer cell inoculation] }\end{array}$ & $\begin{array}{c} \pm 50 \% \text { reduction in tumor } \\
\quad \text { weight } \\
\quad \pm 70 \% \text { reduction in no. of } \\
\text { macroscopic lung metastases }\end{array}$ \\
\hline & $\begin{array}{l}\text { syngeneic; s.c. } \\
\text { colorectal cancer model/9-11 }\end{array}$ & $\begin{array}{l}\text { Rivaroxaban }[0.4 \mathrm{mg} / \mathrm{g} \text { chow diet } \\
\text { for } 9 \text { days, started } 12 \text { days after } \\
\text { cancer cell inoculation] }\end{array}$ & $\begin{array}{l} \pm 40 \% \text { reduction in tumor } \\
\text { volume }\end{array}$ \\
\hline & $\begin{array}{l}\text { spontaneous; } \\
\text { breast cancer model/28 }\end{array}$ & $\begin{array}{l}\text { Rivaroxaban }[0.4 \mathrm{mg} / \mathrm{g} \text { chow diet } \\
\text { for } 7 \text { weeks, started from week } 13 \\
\text { after birth] }\end{array}$ & $\begin{array}{l}\text { reduction in no. of lung } \\
\text { metastases }\end{array}$ \\
\hline $\begin{array}{l}\text { Sophie Featherby } \\
\text { (2019) [48] }\end{array}$ & $\begin{array}{c}\text { syngeneic } \\
\text { the chorioallantoic membrane (CAM) } \\
\text { model } / 3\end{array}$ & $\begin{array}{c}\text { Apixaban }(1 \mu \mathrm{g} / \mathrm{mL}) \\
\text { Rivaroxaban }(0.6 \mu \mathrm{g} / \mathrm{mL})\end{array}$ & $\begin{array}{l}\text { Apixaban }(1 \mu \mathrm{g} / \mathrm{mL}) \text { partially } \\
\text { reduced the growth of the } \\
\text { implanted tumors }\end{array}$ \\
\hline
\end{tabular}

no.-number.

\section{Discussion}

\subsection{Meta-Analysis}

Some of the most recently published meta-analyses comprising thousands of patients diagnosed with cancer-associated VTE showed that those treated with DOAC had a higher risk of bleeding $[21,23,25]$. Most of these bleedings were minor and were found especially in patients with gastrointestinal tumors. Desai R. et al. showed that DOACs are superior to VKA or LMWH for secondary prevention of VTE in patients with cancer, although they have an increased risk for nonmajor bleeding as compared to LMWH [23].

The interpretation of bleeding risks associated with DOACs is complex. Bleeding events associated with DOACs seem to be mostly related to mucosal bleeding. Upper digestive cancer and the use of edoxaban and rivaroxaban were frequently associated with more bleeding events $[24,26]$.

Moreover, bleeding with DOACs may be related to their physiological and pharmacological mechanism of action. Thus, dabigatran, rivaroxaban, and edoxaban may have a topical anticoagulant effect that favors mucosal bleeding, tartaric acid found in dabigatran has a direct caustic effect, while rivaroxaban and edoxaban have pharmacodynamic differences leading to higher peak concentration [49]. To date, DOACs have not been evaluated for the bleeding risk of each representant. However, in one previous meta-analysis (published in 2013) of 43 trials utilizing DOACs for any indication including VTE (but excluding cancer), dabigatran and rivaroxaban were found to be associated with more digestive bleeding and nonmajor bleeding as compared to apixaban [50].

In this respect, Angelini et al. showed that, in presence of neoplasia, patients treated with anticoagulation experienced more bleeding events regardless of the type of DOAC used. Other factors influencing the risk of bleeding in cancer patients were as follows: renal impairment, obesity with a BMI $\geq 40 \mathrm{~kg} / \mathrm{mp}$, the presence of metastatic disease, a moderate to severe thrombocytopenia, and tumor type. In this respect, the authors found 
that regardless of the type of anticoagulant, patients with primary digestive neoplasia had more bleeding events than those with nondigestive cancers [51].

The arguments regarding the safety of different anticoagulants in cancer patients should be established by performing a subgroup meta-analysis of bleeding risk, stratified by cancer type and DOAC type.

\subsection{Randomized Controlled Trials}

The efficacy and safety of LMWHs as compared to VKAs was shown in the following studies: Meyer, Clot, Hull, Deitcher, and Catch [52]. In these studies, the patients treated with LMWHs presented a lower VTE recurrence rate, without an increased risk of major bleeding, as compared to those treated with VKAs [53]. However, LMWH therapy is a burden both financially and socially, requiring daily subcutaneous injections that affect the quality of life. VKAs are sometimes used in cancer patients with increased bleeding risk or VTE recurrence because of the narrow therapeutic range and possible drug interactions found in cancer patients [54].

A number of recent studies show that DOACs have the same efficacy as VKAs and exhibit a better safety profile; thus, they are a potential therapeutic option in patients with paraneoplastic VTE $[29,33,55-57]$. The most important clinical trials that compared DOACs to VKAs in patients with neoplasia are as follows: RE-COVER I and II (dabigatran with VKA), EINSTEIN PE and DVT (rivaroxaban with VKA), AMPLIFY (apixaban with VKA), and Hokusai-VTE (edoxaban with VKA). The results of these clinical trials offer encouraging arguments with regard to the administration of DOACs in paraneoplastic VTE patients (Table 2).

The SELECT-D study included 406 patients with neoplasia and VTE. The subjects were randomly divided into two groups: the first group received rivaroxaban treatment ( $15 \mathrm{mg}$ twice daily for 3 weeks and subsequently $20 \mathrm{mg}$ once daily for 6 months); the second group received dalteparin treatment (200 IU $/ \mathrm{kg}$ for 1 month and subsequently $150 \mathrm{IU} / \mathrm{kg}$ for 2-6 months). VTE recurrence 6 months into the treatment was $11 \%$ in the group undergoing dalteparin treatment and $4 \%$ in the group treated with rivaroxaban. The cumulative risk of major hemorrhages 6 months into the treatment was $4 \%$ with dalteparin treatment as compared to $6 \%$ with rivaroxaban treatment [31].

The ADAM-VTE study included 300 patients who were randomly divided into two groups: the first group was treated with apixaban $(10 \mathrm{mg}$ twice daily for 7 days and subsequently $5 \mathrm{mg}$ twice daily for 6 months); the second group was treated with dalteparin (200 IU $/ \mathrm{kg}$ for 1 month and subsequently $150 \mathrm{IU} / \mathrm{kg}$ for 6 months). The results of this study showed a lower hemorrhage and VTE-recurrence risk in the group treated with apixaban (recurrent VTE was $3.4 \%$ in the group treated with apixaban as compared to $14.1 \%$ in the group treated with dalteparin, major hemorrhages were $0 \%$ in the group treated with apixaban as compared to $2.1 \%$ in the group treated with dalteparin, and the incidence rate of major and nonmajor hemorrhages was the same in both groups, i.e., 9\%) [34].

The CARAVAGGIO study is characterized as a multinational, randomized, investigatorinitiated, open-label, non-inferiority trial with blinded central outcome adjudication. In this study, consecutive patients with cancer diagnosed with symptomatic or incidental acute proximal VTE/PE received either oral apixaban (a dose of $10 \mathrm{mg}$ twice daily for the first week, followed by $5 \mathrm{mg}$ twice daily for 6 months) or subcutaneous dalteparin (a dose of $200 \mathrm{IU}$ per kilogram of body weight once daily for the first month, followed by 150 IU per kilogram once daily for 6 months). The primary outcome was recurrent VTE, which was objectively confirmed. Recurrent VTE frequency was higher in the dalteparin group $(7.9 \%)$ as compared to the apixaban group (5.6\%). On the other hand, no statistically significant differences regarding major bleeding were identified between the two groups ( $3.8 \%$ in the apixaban group and $4 \%$ in the dalteparin group). Thus, apixaban proved to be both effective and safe for the treatment of CAT VTE [35].

The Hokusai-VTE Cancer study included 1046 patients who were randomly divided into two groups: the first group was treated with LMWHs for 5 days and subsequently 
with edoxaban ( $60 \mathrm{mg}$ daily); the second group was treated with dalteparin (200 IU $/ \mathrm{kg}$ during the first month, followed by $150 \mathrm{IU} / \mathrm{kg}$ ). The edoxaban doses were adjusted to renal function and body weight $(30 \mathrm{mg}$ in the case of patients with an eGFR of $30-50 \mathrm{~mL} / \mathrm{min}$, weight $<60 \mathrm{~kg}$, or in the case of an association with antiplatelet aggregation therapy). The risk of recurrent VTE was higher in the group treated with dalteparin, and the risk of major hemorrhages was greater in the group treated with edoxaban. The risk of recurrent VTE was $7.9 \%$ in the group treated with edoxaban as compared to $11.3 \%$ in the group under dalteparin treatment, and the risk of major hemorrhages was $6.9 \%$ in the group treated with edoxaban as compared to $4 \%$ in the group treated with dalteparin. The majority of hemorrhages in the group treated with edoxaban were gastrointestinal hemorrhages due to the gastrointestinal mucous membrane being affected by the toxic effects of the chemotherapeutic agents [30].

There are additional ongoing clinical studies that compare the efficacy and safety of DOAC vs. LMWH administration in neoplastic patients with VTE, e.g., CANVAS: dabigatran, rivaroxaban, apixaban, edoxaban vs. LMWH [36]; CONKO-011: rivaroxaban vs. LMWH [37]; CASTA-DIVA: rivaroxaban vs. LMWH [39]; COSIMO: rivaroxaban vs. LMWH [39].

There are several ongoing studies (one of them being the AVERT study) investigating the risk/benefit ratio in VTE prophylaxis in neoplastic patients with an intermediate and high risk of thrombosis.

\subsection{Guidelines}

In our review, we identified seven national and international guidelines that mention the baseline anticoagulant therapy in cancer patients suffering from VTE.

Until recently, higher adherence to the treatment has been considered one of the advantages of DOACs as compared to LWMH. Patients following an anticoagulant treatment with LMWH, which are administered by subcutaneous injection twice a day, were supposed to give up their treatment more frequently in favor of VTE recurrence $[46,58,59]$. Early this year, Schaefer et al. showed a similarly high rate (95\%) of LMWH and DOAC adherence for patients with CAT. Thus, the authors recommend that anticoagulant therapy should not be guided by the probability of treatment compliance [5].

Edoxaban, rivaroxaban, and apixaban are the only DOACs that have been compared to LMWHs in clinical studies and are accepted for cancer-associated VTE. The use of rivaroxaban in the treatment of these patients is supported by an abundance of clinical evidence. DOACs are associated with a statistically significant lower risk of VTE recurrence in neoplastic patients but with a higher bleeding risk $[20,60,61]$

Some of the guidelines still recommend LMWH as the first-line therapy of cancerassociated VTE, while others recommend DOACs but in appropriate situations, i.e., no drug interactions with current cancer medication, a low risk of bleeding, and normal renal function. Thus, ESC [42] and ASCO [44] suggest the use of LMWH in patients with acute VTE diagnosis (during the first 7-10 days to 6 months) but prefer rivaroxaban to LMWH in patients without gastrointestinal cancer. On the other hand, ISTH [41] and ACCP [43] suggest DOACs in selected categories of patients with acute VTE, a low bleeding risk, and no drug interaction, and suggest LMWH in patients with a high bleeding risk (digestive cancer, genitourinary cancer, and digestive mucosal abnormalities, such as esophagitis, gastritis, colitis, etc.).

\subsection{DOACs beyond Anticoagulation: A Potential Antineoplastic Effect?}

To enhance the indication of DOACs in patients with VTE and cancer, several experimental studies were conducted with the aim of elucidating the possible antineoplastic effect of these drugs.

The antiangiogenetic effect was the first to be targeted in experimental studies. Angiogenesis is a consequence of inflammation and hemostatic disturbances and plays an essential role in tumor progression. Inflammation has a prothrombotic effect as it decreases 
natural anticoagulants, activates platelets, or increases tissue factor (TF) expression. Moreover, both factor $\mathrm{Xa}$ (which represents the target of DOACs) and thrombin initiate and maintain angiogenesis and tissue fibrosis, thus promoting tumoral growth [36]. A schematic presentation of tumor angiogenesis is present in Figure 2. Therefore, experimental studies aimed at demonstrating the antitumoral growth effect of DOACs.

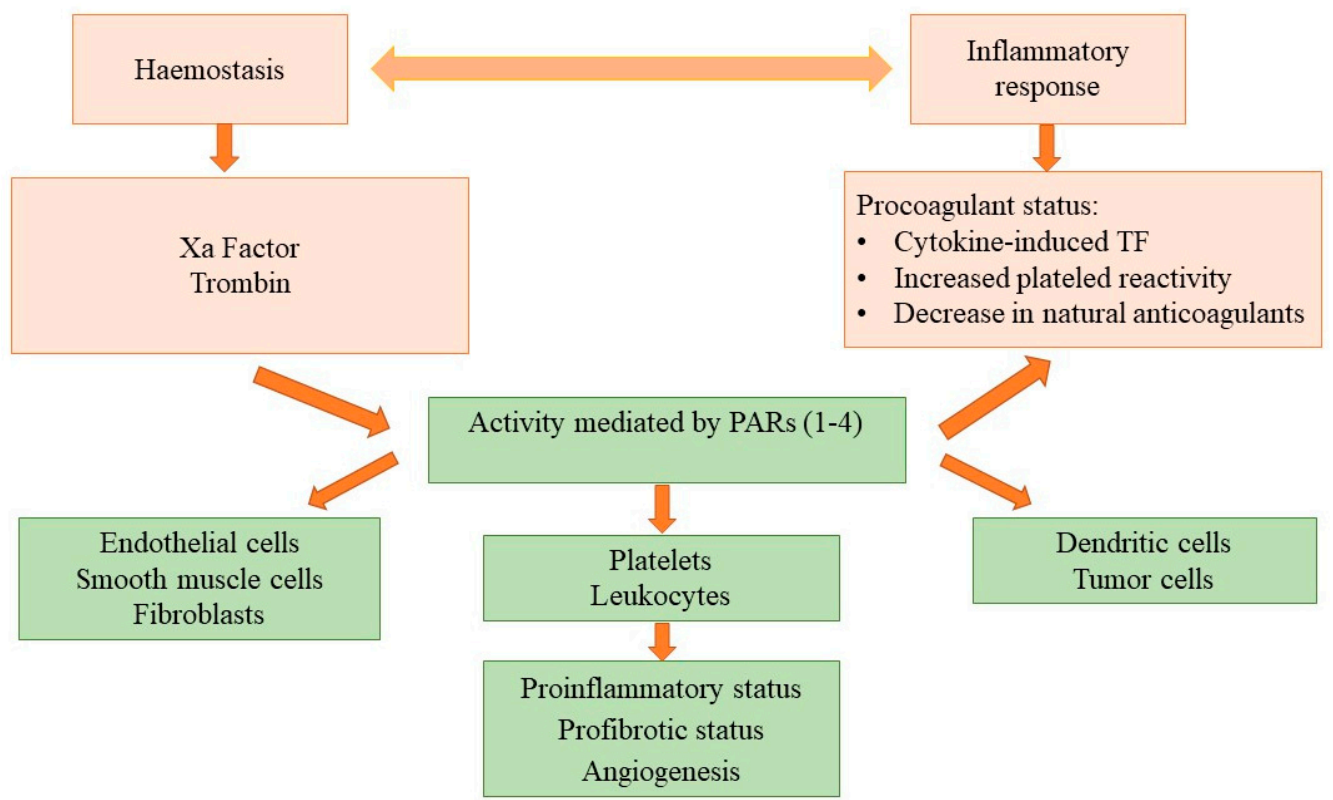

Figure 2. Schematic presentation of tumor angiogenesis (modified from others [36]). TF-tissue factor; PARs-protease-activated receptors.

The results of these studies on reducing the progression of tumors and metastases after DOACs were different and depended on the timing of DOACs and the type of cancer model used. Most of these experimental studies were performed with anticoagulant drugs that are only used in vitro [47]. We selected studies using DOACs approved for use in clinical practice.

The experimental in vitro and in vivo studies were extensively reviewed by Grandoni et al. [36]. Later, Najidh et al. identified nine publications that included a total of 19 in vivo experiments focusing on the effect of DOACs on tumor growth and metastasis [47]. These were animal models of fibrosarcoma, colorectal cancer, pancreatic cancer, melanoma, and breast cancer. Currently, dabigatran, rivaroxaban, and apixaban are the DOACs that have shown an angiogenetic effect.

Dabigatran acts by inhibiting thrombin, and studies on animals have demonstrated a decrease in tumor progression in breast cancer models when treatment is given immediately after the grafting of the neoplastic cells [47].

It has been proved that the timing of administering the treatment is an extremely important fact. However, two other experimental studies in breast cancer in animals showed that if dabigatran was administered when tumors were already established, it had no effect on the development of the primary tumor or on metastases. In a study of pancreatic cancer in mice, it was observed that if dabigatran was administered 1 week after inoculation of the cancer cells, it caused tumor growth, which is explained by the increase in intratumoral bleeding [47].

Rivaroxaban is included in the guidelines for the management of patients with cancerassociated VTE; however, studies showed different results depending on the cancer type. Graf et al. observed that rivaroxaban $(0.4 \mathrm{mg} / \mathrm{g}$ chow diet $)$ reduced fibrosarcoma weight by $50 \%$ and lung metastasis by $70 \%$ at 8 days after administration [62]. On the other hand, Maqsood et al. showed that rivaroxaban $(0.5 \mathrm{mg} / \mathrm{g}$ chow diet $)$ had no effect on tumor size 
or tumoral cell proliferation (quantified by Ki-67-positive tumoral cells) when injected in a xenograft model of pancreatic cancer cells [63].

Another study compared the effect of LMWH (dalteparin and tinzaparin) with DOACs (apixaban and rivaroxaban) on cell proliferation and tumor growth in vitro and in vivo in melanoma and pancreatic cancer models. Dalteparin and tinzaparin reduced tumor growth and tumor invasion in vitro. Apixaban and rivaroxaban treatment did not influence tumor development. A study using the chorioallantoic membrane assay model in vivo demonstrated that in vivo LMWH had a beneficial effect in terms of reducing tumor vascularity and apixaban reduced the rate of tumor proliferation and tumor growth. The results of these studies were explained by the fact that $\mathrm{LMWH}$ acts on tumor development and tumor vascularization by inhibiting factor $\mathrm{Xa}$, inhibiting NFKB cell activity, and decreasing tumor and endothelial cell adhesion through selectins and ICAM receptors [48].

Additional studies are required to determine the potential benefit of DOACs for primary tumor or distant metastasis reduction in laboratory settings before performing clinical studies.

\subsection{Some Practical Considerations on the Use of DOACs in Cancer Patients}

\subsubsection{The Length of the Treatment}

According to the current guidelines, the length of the anticoagulant treatment is 3-6 months. The treatment should be continued indefinitely in patients with active cancer, under chemotherapy, and multiple VTE risk factors $[41,42,46]$. The decision whether to extend the treatment should be reached following the periodic assessment of the hemorrhagic risk against the benefit of the treatment $[45,46]$.

In cases where the VTE-recurrence risk is high, the anticoagulant treatment is administered over an extended period of time (over $3-6$ months) $[43,46,64]$. Various risk scores may be used to stratify the patients' recurrence risk vs. bleeding risk. The Ottawa score, for example, evaluates the 6-month VTE-recurrence risk considering the following variable: sex, cancer type, and previous history of VTE. In the modified score, female sex, lung cancer, and previous history of VTE is each given 1 point, breast cancer and cancer stage I and II receive -1 point [65].

The treatment for these patients needs to be structured according to the location of the neoplasm, major organ functions, patient compliance, concurrent medications, and the existence of other specific factors. For catheter-associated thrombosis, anticoagulant therapy should be administered if a catheter is in place. The recommended total duration of the therapy is at least 3 months [46]. For patients with VTE and cancer, extended anticoagulation (beyond the first 6 months) should be considered for an indefinite period or until the cancer is cured, and the therapeutic dose should be maintained [42,62].

\subsubsection{High Risk of Major Bleeding}

The hemorrhagic risk factors that must be taken into consideration are an age $65>$, prolonged periods of immobilization, the presence of metastases, renal impairment (creatinine clearance below $30 \mathrm{~mL} / \mathrm{min}$ ), and history of digestive hemorrhages, hemorrhagic diathesis, and thrombocytopenia [3]. Currently, no bleeding scores are implemented; however, the IMPROVE score is an example of a bleeding score that is useful in clinical [41] practice. It comprises the following: history of gastroduodenal ulcer, bleeding in the 3 months prior, admission platelets $<50,000 / \mathrm{mm}^{3}$, liver failure, ICU/CCU stay, CV catheter, active cancer, or rheumatic disease [66].

Thrombocytopenia is frequent in neoplastic patients. Its presence increases the risk of bleeding but does not decrease the risk of developing thrombosis. The current guidelines recommend that the anticoagulant treatment be continued, without dose reduction, in cases in which the platelet count exceeds $50,000 / \mathrm{mm}^{3}$. DOACs can be administered at a platelet count $>50,000 / \mathrm{mm}^{3}$, and when the platelet level drops under $50,000 / \mathrm{mm}^{3}$, LMWH should be introduced instead. Each decision should be individualized [67]. In accordance with the ISTH and NCCN guidelines, anticoagulation should be stopped when the platelet 
count is lower than $25,000 / \mathrm{mm}^{3}$, while the ASCO guidelines recommend the withdrawal of the anticoagulants at a threshold of $20,000 / \mathrm{mm}^{3}[41,44,46]$.

According to the current guidelines, DOACs are to be avoided in patients with a high risk of bleeding (luminal gastrointestinal, genitourinary, hematological neoplasms, with nephrostomy, or with an active gastroduodenal ulcer), and LMWHs should be administered instead [41,42].

\subsubsection{Renal Impairment}

The administration of DOACs is not generally recommended in the presence of renal impairment with a $<15 \mathrm{~mL} / \mathrm{min} / \mathrm{m}^{2}$ creatinine clearance. Under careful monitoring, in patients with a creatinine clearance of $15-50 \mathrm{~mL} / \mathrm{min} / \mathrm{m}^{2}$, the following may be used: apixaban $2 \times 2.5 \mathrm{mg} /$ day, edoxaban $(30 \mathrm{mg} /$ day), and rivaroxaban $(15 \mathrm{mg} /$ day $)$.

Although there are attempts to use DOACs in dialysis patients (apixaban $2 \times 2.5 \mathrm{mg}$ ), the use of DOACs in the case of a creatinine clearance below $15 \mathrm{~mL} / \mathrm{min} / \mathrm{m}^{2}$ and dialysis is contraindicated $[45,59]$. For apixaban, a dose reduction is recommended when two of the following three criteria are met: age $\geq 80$ years, weight $\leq 60 \mathrm{~kg}$, and serum creatinine $\geq 1.5 \mathrm{mg} / \mathrm{dL}$ [41].

There are certain issues regarding DOACS dosing in RCT for VTE. Patients with $\mathrm{CrCl}$ $<25 \mathrm{~mL} / \mathrm{min}$ were excluded from the trials testing apixaban, whereas patients with $\mathrm{CrCl}<$ $30 \mathrm{~mL} / \mathrm{min}$ were excluded from those investigating rivaroxaban, edoxaban, and dabigatran. The dosages of dabigatran, rivaroxaban, and apixaban were not reduced in patients with mild-moderate renal dysfunction $(\mathrm{CrCl}$ between $30-60 \mathrm{~mL} / \mathrm{min}$ ), whereas edoxaban was given at a $30 \mathrm{mg}$ dose in these patients [42]. During the first 3 weeks of treatment, it is not recommended to adjust the dose of Rivaroxaban, it should be maintained at $2 \times 15 \mathrm{mg} /$ day, or it should be replaced by LWMH in cases with severe renal impairment.

Grandone et al. have recently published a statement paper regarding the use of DOACs in patients with renal impairment. The paper elegantly summarized the recommendation of three different international societies (2018-2019) regarding the dosing of DOACs adjusted to creatine clearance and reviewed the real-life clinical trials focusing on DOACs in patients with renal impairment. The authors concluded that DOACs are recommended in patients with $\mathrm{CKD}$, but close monitoring is necessary in order to avoid CRNMB [68].

\subsubsection{Liver and Gastrointestinal Diseases}

The oral intake of DOACs is an important drawback, as the absorption might be impaired by nausea and vomiting, symptoms which are relatively frequent in neoplastic patients undergoing chemotherapy.

DOACs absorption is influenced by the anatomic changes in the digestive tube. Rivaroxaban, dabigatran, and edoxaban must be avoided in patients with gastrectomies because they are absorbed in the distal part of the stomach and the proximal part of the small intestine, and they are dependent on gastric acidity for absorption. In such instances, apixaban should be administered because it is absorbed in the distal small bowel and in the ascending colon and is not $\mathrm{pH}$-dependent for absorption [61].

Apixaban should be avoided in patients with intestinal resections and colectomies. Rivaroxaban, dabigatran, or edoxaban should be administered instead. Dabigatran is administered as capsules and should be avoided in the case of tube-fed patients [61].

Apixaban is not to be administered in cases in which transaminase levels are elevated to more than twice the upper limit, while rivaroxaban and edoxaban are not recommended when transaminase levels are three times the upper limit [61].

\subsubsection{Interaction with Other Drugs}

DOACs have fewer interactions than antivitamin $\mathrm{K}$ medication.

Drugs that induce CYP3A4, a cytochrome P450 component present in hepatic cells (rifampicin, carbamazepine, phenobarbital, valproic acid, doxorubicin, vinblastine, suni- 
tinib, vandetanib, and dexamethasone) decrease the anticoagulant effect of apixaban and rivaroxaban. The drugs that inhibit CYP3A4 (dronedarone, diltiazem, clarithromycin, erythromycin, crizotinib, cyclosporine, and tacrolimus) increase the anticoagulant effect of rivaroxaban and apixaban [46].

The P glycoprotein (P-gp) transporter influences and modifies the absorption of dabigatran in the intestines. The P-gp inductors decrease the absorption and the anticoagulant action of dabigatran (rifampicin, dexamethasone, carbamazepine, phenobarbital, phenytoin, levetiracetam, valproic acid, doxorubicin, vinblastine, sunitinib, and vandetanib). The P-gp inhibitors (dronedarone, verapamil, amiodarone, quinidine, clarithromycin, erythromycin, ticagrelor, tacrolimus, cyclosporine, imatinib, and crizotinib) increase dabigatran absorption and its anticoagulant action. The edoxaban dose should be lowered to $30 \mathrm{mg}$ /day when the P-gp inhibitors are concomitantly administered [69]. The interaction of DOACs with antineoplastic therapy is not fully understood and has not yet been investigated in large clinical trials. Bellesoeur et al. analyzed this interaction using the scarce evidence generated by real-life trials. They concluded that "the risk of pharmacokinetic drug-drug interaction with DOAC should be estimated taking account for clinical and biological parameters such as age, sarcopenia, inflammation, renal and hepatic impairment" [70].

\subsubsection{Extreme Weight}

In special cases such as extreme weight, which is frequent in the presence of neoplasia, pharmacological interferences, or suspected noncompliance, monitoring of the DOAC activity may be required. The recommended test for monitoring xabans is the chromogenic antifactory Xa assay. The ranges are $12-137 \mathrm{ng} / \mathrm{mL}$ for rivaroxaban and $34-230 \mathrm{ng} / \mathrm{mL}$ for apixaban. The recommended tests for monitoring dabigatran are the dilute thrombin time (DTT) test and the ecarin clotting time (ECT) test [46]. For patients weighing less than $60 \mathrm{~kg}$, a lower dose of edoxaban $(30 \mathrm{mg} / \mathrm{dl})$ should be administered [42].

\section{Conclusions}

The anticoagulant treatment of cancer-associated VTE is difficult to administer because patients have a high risk of recurrence and bleeding.

DOACs exhibit a similar efficiency as VKAs for the treatment of cancer-associated VTE and a lower risk of bleeding. DOACs are more efficient and easier to administer as compared to LMWHs in the prevention of VTE recurrence, but they can be associated with a higher risk of bleeding.

Thus, we support the administration of DOACs as the first-choice treatment in cancerassociated VTE in patients who have a low risk of bleeding under anticoagulant treatment, who do not have severe renal impairment, and who are not undergoing treatments that could interact with the DOAC mechanism of action.

DOACs may also have an antineoplastic effect which depends on the type of cancer and on the early start of the treatment, but more studies are required to support this hypothesis.

Author Contributions: Conceptualization: R.M.C. and M.M.; software S.C. and C.M.G.; validation M.M. and A.D.F.; resources R.M.C.; data curation, A.B.; writing—original draft preparation, R.M.C. and A.B.; writing-review and editing, R.M.C. and M.M.; visualization, S.C. and M.A.S.; supervision, A.D.F. All authors have read and agreed to the published version of the manuscript.

Funding: This research received no external funding.

Institutional Review Board Statement: Not applicable.

Informed Consent Statement: Not applicable.

Data Availability Statement: Not applicable.

Acknowledgments: The authors want to thank Seulean Tudor for his great support in editing the manuscript. 
Conflicts of Interest: The authors declare no conflict of interest.

\section{References}

1. Borovac, J.A.; D'Amario, D.; Bozic, J.; Glavas, D. Sympathetic Nervous System Activation and Heart Failure: Current State of Evidence and the Pathophysiology in the Light of Novel Biomarkers. World J. Cardiol. 2020, 12, 373-408. [CrossRef] [PubMed]

2. Timp, J.; Braekkan, S.; Versteeg, H.; Cannegieter, S. Epidemiology of cancer-associated venous thrombosis. Blood J. Am. Soc. Hematol. 2013, 122, 1712-1723. [CrossRef] [PubMed]

3. Mosarla, R.C.; Vaduganathan, M.; Qamar, A.; Moslehi, J.; Piazza, G.; Giugliano, R.P. Anticoagulation Strategies in Patients With Cancer: JACC Review Topic of the Week. J. Am. Coll. Cardiol. 2019, 73, 1336-1349. [CrossRef] [PubMed]

4. Kearon, C.; Akl, E.A.; Ornelas, J.; Blaivas, A.; Jimenez, D.; Bounameaux, H.; Huisman, M.; King, C.S.; Morris, T.A.; Sood, N.; et al Antithrombotic therapy for VTE disease: CHEST guideline and expert panel report. Chest 2016, 149, 315-352. [CrossRef]

5. Schaefer, J.K.; Li, M.; Wu, Z.; Basu, T.; Dorsch, M.P.; Barnes, G.D.; Carrier, M.; Griggs, J.J.; Sood, S.L. Anticoagulant medication adherence for cancer-associated thrombosis: A comparison of LMWH to DOACs. J. Thromb. Haemost. 2021, 19, 212-220. [CrossRef]

6. Liberati, A.; Shamseer, L.; Moher, D.; Clarke, M.; Ghersi, D.; Petticrew, M.; Shekelle, P.; Stewart, L.A. PRISMA-P (Preferred Reporting Items for Systematic review and Meta-Analysis Protocols) 2015 checklist: Recommended items to address in a systematic review protocol. BMJ 2015, 349, g7647. [CrossRef]

7. Sardar, P.; Chatterjee, S.; Herzog, E.; Pekler, G.; Mushiyev, S.; Pastori, L.J.; Visco, F.; Aronow, W.S. New oral anticoagulants in patients with cancer: Current state of evidence. Am. J. Ther. 2015, 22, 460-468. [CrossRef]

8. Posch, F.; Königsbrügge, O.; Zielinski, C.; Pabinger, I.; Ay, C. Treatment of venous thromboembolism in patients with cancer: A network meta-analysis comparing efficacy and safety of anticoagulants. Thromb. Res. 2015, 136, 582-589. [CrossRef]

9. Mantha, S.; Ansell, J. Indirect comparison of dabigatran, rivaroxaban, apixaban and edoxaban for the treatment of acute venous thromboembolism. J. Thromb. Thrombolysis 2015, 39, 155-165. [CrossRef] [PubMed]

10. Boonyawat, K.; Caron, F.; Li, A.; Chai-Adisaksopha, C.; Lim, W.; Iorio, A.; Lopes, R.D.; Garcia, D.; Crowther, M.A. Association of body weight with efficacy and safety outcomes in phase III randomized controlled trials of direct oral anticoagulants: A systematic review and meta-analysis. J. Thromb. Haemost. 2017, 15, 1322-1333. [CrossRef] [PubMed]

11. Kahale, L.A.; Hakoum, M.B.; Tsolakian, I.G.; Matar, C.F.; Barba, M.; Yosuico, V.E.D.; Terrenato, I.; Sperati, F.; Schünemann, H.; Akl, E.A. Oral anticoagulation in people with cancer who have no therapeutic or prophylactic indication for anticoagulation. Cochrane Database Syst. Rev. 2017, 12, CD006466. [CrossRef]

12. Hakoum, M.B.; Kahale, L.A.; Tsolakian, I.G.; Matar, C.F.; Yosuico, V.E.; Terrenato, I.; Sperati, F.; Barba, M.; Schünemann, H.; Akl, E.A. Anticoagulation for the initial treatment of venous thromboembolism in people with cancer (Review). Cochrane Database Syst. Rev. 2018. [CrossRef]

13. Vedovati, M.C.; Giustozzi, M.; Bonitta, G.; Agnelli, G.; Becattini, C. Efficacy and safety of anticoagulant agents in patients with venous thromboembolism and cancer: A network meta-analysis. Thromb. Res. 2018, 170, 175-180. [CrossRef]

14. Xing, J.; Yin, X.; Chen, D. Rivaroxaban versus enoxaparin for the prevention of recurrent venous thromboembolism in patients with cancer: A meta-analysis. Medicine 2018, 97, e11384. [CrossRef]

15. Martinez, B.K.; Sheth, J.; Patel, N.; Baker, W.L.; Coleman, C.I. Systematic Review and Meta-Analysis of Real-World Studies Evaluating Rivaroxaban for Cancer-Associated Venous Thrombosis. Pharmacotherapy 2018, 38, 610-618. [CrossRef] [PubMed]

16. Park, H.; Kim, J.-C.; Cho, J.; Lim, J.H.; Lee, M.H. Systematic literature review and network meta-analysis of oral anticoagulants for the treatment of venous thromboembolism in patients with cancer. Ann. Oncol. 2018, 29, viii615. [CrossRef]

17. Hong, Y.; Mansour, S.; Alotaibi, G.; Wu, C.; McMurtry, M.S. Effect of anticoagulants on admission rates and length of hospital stay for acute venous thromboembolism: A systematic review of randomized control trials. Crit. Rev. Oncol. Hematol. 2018, 125, 12-18. [CrossRef] [PubMed]

18. Gómez-Outes, A.; Terleira-Fernández, A.I.; Lecumberri, R.; Suárez-Gea, M.L.; Calvo-Rojas, G.; Vargas-Castrillón, E. Causes of Death in Patients with Venous Thromboembolism Anticoagulated with Direct Oral Anticoagulants: A Systematic Review and Meta-Analysis. Semin. Thromb. Hemost. 2018, 44, 377-387. [CrossRef]

19. Li, A.; Garcia, D.A.; Lyman, G.H.; Carrier, M. Direct oral anticoagulant (DOAC) versus low-molecular-weight heparin (LMWH) for treatment of cancer associated thrombosis (CAT): A systematic review and meta-analysis. Thromb. Res. 2018, 173, 158-163. [CrossRef]

20. Rossel, A.; Robert-Ebadi, H.; Combescure, C.; Grosgurin, O.; Stirnemann, J.; Addeo, A.; Garin, N.; Agoritsas, T.; Reny, J.L.; Marti, C. Anticoagulant therapy for acute venous thrombo-embolism in cancer patients: A systematic review and network meta-analysis. PLoS ONE 2019, 14, e0213940. [CrossRef] [PubMed]

21. Kirkilesis, G.I.; Kakkos, S.K.; Tsolakis, I.A. Editor's Choice-A Systematic Review and Meta-Analysis of the Efficacy and Safety of Anticoagulation in the Treatment of Venous Thromboembolism in Patients with Cancer. Eur. J. Vasc. Endovasc. Surg. 2019, 57, 685-701. [CrossRef]

22. Camilli, M.; Lombardi, M.; Vescovo, G.M.; Del Buono, M.G.; Galli, M.; Aspromonte, N.; Zoccai, G.B.; Niccoli, G.; Montone, R.A.; Crea, F.; et al. Efficacy and safety of novel oral anticoagulants versus low molecular weight heparin in cancer patients with venous thromboembolism: A systematic review and meta-analysis. Crit. Rev. Oncol. Hematol. 2020, 154, 1-9. [CrossRef] 
23. Desai, R.; Koipallil, G.K.; Thomas, N.; Mhaskar, R.; Visweshwar, N.; Laber, D.; Patel, A.; Jaglal, M. Efficacy and safety of direct oral anticoagulants for secondary prevention of cancer associated thrombosis: A meta-analysis of randomized controlled trials. Sci. Rep. 2020, 10, 773. [CrossRef]

24. Sabatino, J.; De Rosa, S.; Polimeni, A.; Sorrentino, S.; Indolfi, C. Direct Oral Anticoagulants in Patients With Active Cancer: A Systematic Review and Meta-Analysis. JACC CardioOncology 2020, 2, 428-440. [CrossRef] [PubMed]

25. Desai, A.; Gyawali, B. Assessing the benefits and harms of direct oral anticoagulants in patients with cancer for the prophylaxis and treatment of venous thromboembolism: A systematic review and meta-analysis. Ecancermedicalscience 2020, $14,1091$. [CrossRef] [PubMed]

26. Moik, F.; Posch, F.; Zielinski, C.; Pabinger, I.; Ay, C. Direct oral anticoagulants compared to low-molecular-weight heparin for the treatment of cancer-associated thrombosis: Updated systematic review and meta-analysis of randomized controlled trials. Res. Pract. Thromb. Haemost. 2020, 4, 550-561. [CrossRef]

27. Goldhaber, S.Z.; Schellong, S.; Kakkar, A.; Eriksson, H.; Feuring, M.; Kreuzer, J.; Fraessdorf, M.; Schulman, S. Treatment of acute pulmonary embolism with dabigatran versus warfarin: A pooled analysis of data from RE-COVER and RE-COVER II. Thromb. Haemost. 2016, 116, 714-721. [CrossRef]

28. Cohen, A.T.; Bauersachs, R. Rivaroxaban and the Einstein clinical trial programme. Blood Coagul. Fibrinolysis 2019, 30, 85-95. [CrossRef]

29. Agnelli, G.; Buller, H.R.; Cohen, A.; Gallus, A.S.; Lee, T.C.; Pak, R.; Raskob, G.E.; Weitz, J.I.; Yamabe, T. Oral apixaban for the treatment of venous thromboembolism in cancer patients: Results from the AMPLIFY trial. J. Thromb. Haemost. 2015, 13, 2187-2191. [CrossRef] [PubMed]

30. Raskob, G.E.; Van Es, N.; Verhamme, P.; Carrier, M.; Di Nisio, M.; Garcia, D.; Grosso, M.A.; Kakkar, A.K.; Kovacs, M.J.; Mercuri, M.F.; et al. Edoxaban for the treatment of cancer-associated venous thromboembolism. N. Engl. J. Med. 2018, 378, 615-624. [CrossRef]

31. Young, A.M.; Marshall, A.; Thirlwall, J.; Chapman, O.; Lokare, A.; Hill, C.; Hale, D.; Dunn, J.A.; Lyman, G.H.; Hutchinson, C.; et al. Comparison of an oral factor xa inhibitor with low molecular weight heparin in patients with cancer with venous thromboembolism: Results of a randomized trial (SELECT-D). J. Clin. Oncol. 2018, 36, 2017-2023. [CrossRef] [PubMed]

32. Ageno, W.; Mantovani, L.G.; Haas, S.; Kreutz, R.; Monje, D.; Schneider, J.; van Eickels, M.; Gebel, M.; Turpie, A.G.G. Subgroup Analysis of Patients with Cancer in XALIA: A Noninterventional Study of Rivaroxaban versus Standard Anticoagulation for VTE. TH Open Companion J. Thromb. Haemost. 2017, 1, e33-e42. [CrossRef]

33. Soff, G.A.; Mones, J.; Wilkins, C.; Devlin, S.; Haegler-Laube, E.; Wills, J.; Sarasohn, D.M.; Juluru, K.; Singer, M.; Miao, Y.; et al Rivaroxaban treatment of cancer-associated venous thromboembolism: Memorial Sloan Kettering Cancer Center institutional experience. Res. Pract. Thromb. Haemost. 2019, 3, 349-356. [CrossRef] [PubMed]

34. McBane, R.D.; Wysokinski, W.E.; Le-Rademacher, J.G.; Zemla, T.; Ashrani, A.; Tafur, A.; Perepu, U.; Anderson, D.; Gundabolu, K.; Kuzma, C.; et al. Apixaban and dalteparin in active malignancy-associated venous thromboembolism: The ADAM VTE trial. $J$. Thromb. Haemost. 2020, 18, 411-421. [CrossRef]

35. Agnelli, G.; Becattini, C.; Meyer, G.; Muñoz, A.; Huisman, M.V.; Connors, J.M.; Cohen, A.; Bauersachs, R.; Brenner, B.; Torbicki, A.; et al. Apixaban for the treatment of venous thromboembolism associated with cancer. N. Engl. J. Med. 2020, 382, 1599-1607. [CrossRef]

36. Grandoni, F.; Alberio, L. Direct oral anticoagulant drugs: On the treatment of cancer-related venous thromboembolism and their potential anti-neoplastic effect. Cancers 2019, 11, 46. [CrossRef]

37. Riess, H.; Sinn, M.; Kreher, S. CONKO-011: Evaluation of patient satisfaction with the treatment of acute venous thromboembolism with rivaroxaban or low molecular weight heparin in cancer patients. A randomized phase III study. Dtsch. Med. Wochenschr. 2015, 140, S22-S23. [CrossRef]

38. CASTA-DIVA. ClinicalTrials.gov Identifier: NCT02746185. Available online: https://clinicaltrials.gov/ct2/show /NCT02746185 (accessed on 31 January 2018).

39. Khorana, A.A.; Weitz, J.I. Treatment Challenges in Venous Thromboembolism: An Appraisal of Rivaroxaban Studies. Thromb. Haemost. 2018, 118, S23-S33. [CrossRef]

40. Carrier, M.; Blais, N.; Crowther, M.; Kavan, P.; Le Gal, G.; Moodley, O.; Shivakumar, S.; Tagalakis, V.; Wu, C.; Lee, A.Y.Y. Treatment algorithm in cancer-associated thrombosis: Canadian expert consensus. Curr. Oncol. 2018, 25, 329-337. [CrossRef]

41. Khorana, A.A.; Noble, S.; Lee, A.Y.Y.; Soff, G.; Meyer, G.; O'Connell, C.; Carrier, M. Role of direct oral anticoagulants in the treatment of cancer-associated venous thromboembolism: Guidance from the SSC of the ISTH. J. Thromb. Haemost. 2018, 16, 1891-1894. [CrossRef] [PubMed]

42. Konstantinides, S.V.; Meyer, G.; Becattini, C.; Bueno, H.; Geersing, G.-J.; Harjola, V.-P.; Huisman, M.V.; Humbert, M.; Jennings, C.S.; Jiménez, D.; et al. 2019 ESC Guidelines for the diagnosis and management of acute pulmonary embolism developed in collaboration with the European Respiratory Society (ERS). Eur. Heart J. 2019, 41, 1-61. [CrossRef] [PubMed]

43. Franco-Moreno, A.; Cabezon-Gutierrez, L.; Palka-Kotlowsa, M.; Villamayor-Delgado, M.; Garcia-Navarro, M. Evaluation of direct oral anticoagulants for the treatment of cancer-associated thrombosis: An update. J. Thromb. Thrombolysis 2019, 47, 409-419. [CrossRef]

44. Verso, M.; Di Nisio, M. Management of venous thromboembolism in cancer patients: Considerations about the clinical practice guideline update of the American society of clinical oncology. Eur. J. Intern. Med. 2020, 71, 4-7. [CrossRef] [PubMed] 
45. Tran, H.A.; Gibbs, H.; Merriman, E.; Curnow, J.L.; Young, L.; Bennett, A.; Wee, T.C.; Chunilal, S.D.; Ward, C.M.; Baker, R.; et al. New guidelines from the Thrombosis and Haemostasis Society of Australia and New Zealand for the diagnosis and management of venous thromboembolism. Med. J. Aust. 2019, 210, 227-235. [CrossRef]

46. Streiff, M.B.; Holmstrom, B.; Angelini, D.; Ashrani, A.; Bockenstedt, P.L.; Chesney, C.; Fanikos, J.; Fenninger, R.B.; Fogerty, A.E.; Gao, S.; et al. NCCN Guidelines®insights cancer-associated venous thromboembolic disease, version 2.2018 featured updates to the NCCN guidelines. JNCCN J. Natl. Compr. Cancer Netw. 2018, 16, 1289-1303. [CrossRef] [PubMed]

47. Najidh, S.; Versteeg, H.H.; Buijs, J.T. A systematic review on the effects of direct oral anticoagulants on cancer growth and metastasis in animal models. Thromb. Res. 2020, 187, 18-27. [CrossRef] [PubMed]

48. Featherby, S.; Xiao, Y.P.; Ettelaie, C.; Nikitenko, L.L.; Greenman, J.; Maraveyas, A. Low molecular weight heparin and direct oral anticoagulants influence tumour formation, growth, invasion and vascularisation by separate mechanisms. Sci. Rep. 2019, 9, 1-13. [CrossRef]

49. Cîmpan, P.L.; Chira, R.I.; Mocan, M.; Anton, F.P.; Farcaş, A.D. Oral Anticoagulant Therapy—When Art Meets Science. J. Clin. Med. 2019, 8, 1747. [CrossRef]

50. Holster, I.L.; Valkhoff, V.E.; Kuipers, E.J.; Tjwa, E.T.T.L. New oral anticoagulants increase risk for gastrointestinal bleeding: A systematic review and meta-analysis. Gastroenterology 2013, 145, 105-112.e15. [CrossRef]

51. Angelini, D.E.; Radivoyevitch, T.; McCrae, K.R.; Khorana, A.A. Bleeding incidence and risk factors among cancer patients treated with anticoagulation. Am. J. Hematol. 2019, 94, 780-785. [CrossRef]

52. Young, A. Cancer Associated Thrombosis: Scope of the Problem; Patient Perspective; 2019. Available online: https://thrombosisuk.org/ (accessed on 31 January 2018).

53. Meyer, G. Low-molecular weight heparin or direct oral anticoagulants for the treatment of cancer associated thrombosis. Are we at the crossroad? Thromb. Res. 2019, 173, 156-157. [CrossRef] [PubMed]

54. Key, N.S.; Khorana, A.A.; Kuderer, N.M.; Bohlke, K.; Lee, A.Y.Y.; Arcelus, J.I.; Wong, S.L.; Balaban, E.P.; Flowers, C.R.; Francis, C.W.; et al. Venous Thromboembolism Prophylaxis and Treatment in Patients With Cancer: ASCO Clinical Practice Guideline Update. J. Clin. Oncol. 2019, 38, 496-520. [CrossRef] [PubMed]

55. Schulman, S.; Goldhaber, S.Z.; Kearon, C.; Kakkar, A.K.; Schellong, S.; Eriksson, H.; Hantel, S.; Feuring, M.; Kreuzer, J. Treatment with dabigatran or warfarin in patients with venous thromboembolism and cancer. Thromb. Haemost. 2015, 114, 150-157. [CrossRef] [PubMed]

56. Prins, M.H.; Lensing, A.W.A.; Brighton, T.A.; Lyons, R.M.; Rehm, J.; Trajanovic, M.; Davidson, B.L.; Beyer-Westendorf, J.; Pap, Á.F.; Berkowitz, S.D.; et al. Oral rivaroxaban versus enoxaparin with vitamin $\mathrm{K}$ antagonist for the treatment of symptomatic venous thromboembolism in patients with cancer (EINSTEIN-DVT and EINSTEIN-PE): A pooled subgroup analysis of two randomised controlled trials. Lancet. Haematol. 2014, 1, e37-e46. [CrossRef]

57. Raskob, G.E.; van Es, N.; Segers, A.; Angchaisuksiri, P.; Oh, D.; Boda, Z.; Lyons, R.M.; Meijer, K.; Gudz, I.; Weitz, J.I.; et al. Edoxaban for venous thromboembolism in patients with cancer: Results from a non-inferiority subgroup analysis of the Hokusai-VTE randomised, double-blind, double-dummy trial. Lancet. Haematol. 2016, 3, e379-e387. [CrossRef]

58. Ramacciotti, E.; Agati, L.B.; Caffaro, R.A.; Volpiani, G.G.; Lopes, R.D.; Comerota, A.J.; Fareed, J. Direct Oral Anticoagulants and Cancer-Associated Thrombosis Management. Where Do We Stand in 2019? Clin. Appl. Thromb. 2019, 25, 1-7. [CrossRef]

59. Carrier, M.; Soff, G.; Le Gal, G. Treatment of Venous Thromboembolism in Cancer. Historical Perspective and Evolving Role of the Direct Oral Anticoagulants. Cancer Treat. Res. 2019, 179, 103-115. [CrossRef]

60. Fokin, A.A.; Bagaev, K.V. Venous thromboembolic complications in oncological patients: Present-day possibilities of effective and safe anticoagulant therapy. Angiol. Sosud. Khir. 2019, 25, 19-23. [CrossRef]

61. Kim, S.A.; Yhim, H.Y.; Bang, S.M. Current management of cancer-associated venous thromboembolism: Focus on direct oral anticoagulants. J. Korean Med. Sci. 2019, 34. [CrossRef]

62. Graf, C.; Wilgenbus, P.; Pagel, S.; Pott, J.; Marini, F.; Reyda, S.; Kitano, M.; Macher-Göppinger, S.; Weiler, H.; Ruf, W. Myeloid cell-synthesized coagulation factor X dampens antitumor immunity. Sci. Immunol. 2019, 4, 1-14. [CrossRef]

63. Maqsood, A.; Hisada, Y.; Garratt, K.B.; Homeister, J.; Mackman, N. Rivaroxaban does not affect growth of human pancreatic tumors in mice. J. Thromb. Haemost. 2019, 17, 2169-2173. [CrossRef] [PubMed]

64. Ay, C.; Beyer-Westendorf, J.; Pabinger, I. Treatment of cancer-associated venous thromboembolism in the age of direct oral anticoagulants. Ann. Oncol. Off. J. Eur. Soc. Med. Oncol. 2019, 30, 897-907. [CrossRef] [PubMed]

65. Delluc, A.; Miranda, S.; Den Exter, P.; Louzada, M.; Alatri, A.; Ahn, S.; Monreal, M.; Khorana, A.; Huisman, M.V.; Wells, P.S.; et al. Accuracy of the Ottawa score in risk stratification of recurrent venous thromboembolism in patients with cancer-associated venous thromboembolism: A systematic review and meta-analysis. Haematologica 2020, 105, 1436-1442. [CrossRef] [PubMed]

66. Decousus, H.; Tapson, V.F.; Bergmann, J.F.; Chong, B.H.; Froehlich, J.B.; Kakkar, A.K.; Merli, G.J.; Monreal, M.; Nakamura, M.; Pavanello, R.; et al. Factors at admission associated with bleeding risk in medical patients: Findings from the improve investigators. Chest 2011, 139, 69-79. [CrossRef]

67. Moik, F.; Pabinger, I.; Ay, C. How i treat cancer-associated thrombosis. ESMO Open 2020, 4, 1-8. [CrossRef]

68. Grandone, E.; Aucella, F.; Barcellona, D.; Brunori, G.; Forneris, G.; Gresele, P.; Marietta, M.; Poli, D.; Testa, S.; Tripodi, A.; et al. Position paper on the safety/efficacy profile of Direct Oral Anticoagulants in patients with Chronic Kidney Disease: Consensus document of Società Italiana di Nefrologia (SIN), Federazione Centri per la diagnosi della trombosi e la Sorveglianza delle tera. J. Nephrol. 2021, 34, 31-38. [CrossRef] 
69. Riess, H.; Prandoni, P.; Harder, S.; Kreher, S.; Bauersachs, R. Direct oral anticoagulants for the treatment of venous thromboembolism in cancer patients: Potential for drug-drug interactions. Crit. Rev. Oncol. Hematol. 2018, 132, 169-179. [CrossRef]

70. Bellesoeur, A.; Thomas-Schoemann, A.; Allard, M.; Smadja, D.; Vidal, M.; Alexandre, J.; Goldwasser, F.; Blanchet, B. Pharmacokinetic variability of anticoagulants in patients with cancer-associated thrombosis: Clinical consequences. Crit. Rev. Oncol. Hematol. 2018, 129, 102-112. [CrossRef] [PubMed] 